Recebido: 30/10/2018

Aprovado: 29/01/2019

\title{
Conflitos e pedidos de terra nas cartas dos trabalhadores para Getúlio Vargas e Juan Domingo Perón
}

Mayra Coan Lago ${ }^{1}$

Resumo: Nosso objetivo é analisar e comparar os pedidos e os conflitos de terra presentes nas cartas dos trabalhadores brasileiros para Getúlio Vargas, durante o Estado Novo (1937-1945), e dos argentinos para Juan Domingo Perón, durante o Primeiro Peronismo (1946-1955). As correspondências foram recebidas e trabalhadas por órgãos governamentais específicos, como a Secretaria da Presidência da República no Brasil e a Secretaria de Assuntos Técnicos, posteriormente Ministério de Assuntos Técnicos, na Argentina. A análise permite o contato com as múltiplas compreensões conjunturais, percepções de si e concepções dos projetos políticos dos governantes sob o ponto de vista dos que viviam nos rincões brasileiros e argentinos. Finalmente, é possível observarmos as apropriações e os usos dos imaginários políticos governamentais por estas

\footnotetext{
${ }^{1}$ Doutoranda em História no Programa de História Social da Universidade de São Paulo e bolsista do Conselho Nacional de Desenvolvimento Científico e Tecnológico (CNPq). Mestre pelo Programa de PósGraduação em Integração da América Latina da Universidade de São Paulo (PROLAM/USP). E-mail: mcoann@hotmail.com
} 
pessoas para expressarem suas aspirações, necessidades e fazerem as suas reivindicações.

Palavras-chaves: cartas; varguismo; peronismo.

Em novembro de 1937, Getúlio Vargas desferiu um golpe e promulgou uma nova Constituição, que legalizou um aparato de medidas destinadas a estreitar os espaços das liberdades políticas, controlar os movimentos dos trabalhadores, disciplinar a mão-deobra e industrializar o país. O Estado intervencionista promoveu sua legitimidade na defesa do desenvolvimento econômico, nas integrações do país (política, social e territorial), na promulgação dos direitos trabalhistas e sociais e na construção do progresso dentro da ordem. Segundo Maria Helena Capelato (2009), durante o Estado Novo, Vargas contou com o apoio das Forças Armadas, da Igreja, de parte dos trabalhadores e dos proprietários.

Nove anos mais tarde, em 1946, Juan Domingo Perón, que já havia participado do governo da “Revolução Nacional” (1943-1945)- ocupando os cargos de Vice-Presidente, Ministro de Guerra, Presidente do Conselho de Pós-Guerra e Secretário de Trabalho e Previdência- vence as eleições pelo Partido Laborista, governando o país até 1951, quando foi reeleito para o cargo pelo Partido Peronista. Em 1955, Perón foi derrubado por um golpe militar.

Durante o primeiro governo, Perón contou com o apoio de parte dos trabalhadores, de grupos nacionalistas, de setores das Forças Armadas e da Igreja. Nesse contexto, a conjuntura internacional foi muito favorável para a Argentina. Com o fim da Guerra, o país devedor tornou-se credor graças à colocação de seus produtos agropecuários no mercado europeu em guerra. No âmbito econômico, o governo peronista tentou reforçar a indústria com a ajuda da agricultura, reduzir a influência estrangeira na economia e outorgar ao Estado o papel decisivo na regulamentação da economia através de dois Planos Quinquenais (1946-1951; 1952-1957). Tal situação contribuiu para a melhoria do nível de vida dos argentinos, sobretudo dos setores mais carentes. Essa conquista permitiu que a propaganda política peronista propagasse a imagem da Argentina como um "mundo feliz”. Já o segundo governo foi marcado por crise econômica, inflação, suspensão de subsídios públicos, queda de salários e a morte de Eva Perón. Assim, Perón teve que lidar

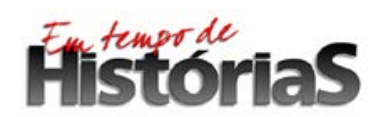


com o descontentamento de parte dos grupos nacionalistas, dos trabalhadores e da Igreja, que acabou rompendo com o governo.

Durante seus governos, os presidentes brasileiro e argentino receberam milhares de cartas, que foram enviadas por nacionais e estrangeiros, provenientes de todo o país e de fora dele ${ }^{2}$. Nosso objetivo é analisar e comparar uma das temáticas destas missivas, referente aos conflitos e pedidos de terras no Brasil estadonovista e na Argentina peronista, que foram enviadas pelos trabalhadores brasileiros para Getúlio Vargas e argentinos para Juan Domingo Perón. Para lograr o objetivo consideraremos principalmente as cartas de homens e mulheres, provenientes destes espaços, mas também as que se referem aos mesmos, isto é, incluiremos as cartas dos mediadores dos trabalhadores e dos comentadores da situação do campo e do interior, por acreditarmos que assim teremos um panorama mais amplo e complexo do período estudado. A própria concepção de “campo” e de “interior” também deve ser esclarecida à luz do que estas pessoas consideraram. Para a grande maioria dos remetentes, significavam os locais mais afastados dos centros urbanos ou das capitais, por vezes também identificados como o lugar do desamparo, da desordem e do atraso.

Ante a historiografia tradicional sobre o período, que demarcou o campo com os estudos sobre o “populismo” e que, de maneira geral, desconsiderou estes trabalhadores nos estudos destes governos, consideramos emblemático encontrarmos muitos trabalhadores rurais ou do interior como remetentes. No momento trabalhamos com 3357 cartas, sendo 1911 do Brasil e 1446 da Argentina. Em ambos os países, o tema correlato ao campo/interior foi o segundo mais mencionado nas cartas que estudamos, sendo 322 brasileiras e 185 argentinas, representando 17\% e $13 \%$, respectivamente, do montante total, e ficando atrás apenas de emprego, no caso do Brasil, e de vida, no caso da Argentina. Se formos considerar a procedência, com temáticas variadas, no Brasil tivemos a participação de praticamente todos os estados do Norte e do Nordeste, sendo que Bahia, Ceará, Pernambuco, Paraíba e Rio Grande do Norte figuram entre os dez primeiros dos vinte e dois estados da época.

\footnotetext{
${ }^{2}$ Este artigo é parte de um projeto mais amplo de doutorado, ainda em curso, cujo objetivo é analisar e comparar as construções dos imaginários sociais no Estado Novo e no Primeiro Peronismo a partir das cartas das "pessoas comuns" para os dois presidentes. Devido ao grande número de correspondências encontradas nos Arquivos Nacionais correspondentes, optamos por trabalhar somente com as que tratam de temáticas sociais. Ou seja, com aquelas que versam sobre as questões cotidianas de vida e de trabalho destas pessoas, homens e mulheres, nacionais e estrangeiros, provenientes dos mais distintos rincões do Brasil e da Argentina.
} 
O mesmo ocorreu na Argentina, sendo que as províncias do Norte e do Nordeste do território, como Santa Fé, Entre Rios, Tucumán, San Juan, Eva Perón (hoje La Pampa) e Corrientes figuraram entre os dez primeiras das vinte e três províncias. Além destas regiões, há que se considerar os locais mais afastados, sobretudo das duas capitais da época, como a grande Buenos Aires e a baixada fluminense, além das cidades do interior de São Paulo. Estes dados revelam que estas pessoas não eram uma massa amorfa e que não foram completamente desconsiderados pelas políticas e propagandas “populistas”.

De acordo com Capelato (2009), nos anos 1920, com a diminuição do fluxo imigratório europeu, o trabalhador nacional passou a ser visto como o substituto do imigrante. No entanto, deveria ser transformado em força produtiva, para contribuir com o progresso nacional. Estamos de acordo com Vanderlei Vazelesk Ribeiro (2008) ao afirmar que a agricultura e a pecuária eram a fonte principal para arrecadar recursos, seja para quitar compromissos externos ou para incentivar a indústria nascente. No Brasil dos anos 1930, parte da industrialização teve seu financiamento proveniente dos impostos sobre o café exportado, seguido de outros produtos, enquanto na Argentina dos anos 1940, a agricultura gerou alimento para um país mais urbanizado.

No que se refere à preocupação e às políticas para os trabalhadores rurais, no caso brasileiro, estamos de acordo com Marcus Dezemone (2012) ao afirmar que a menção aos trabalhadores rurais decorreu de dois aspectos políticos mais amplos. O primeiro abarca os esforços da intelectualidade brasileira, sobretudo a partir do movimento modernista, de estudar as origens e os rumos da nação, tal como a "brasilidade”. Reconhecendo o peso do passado colonial e do mundo rural, foi preciso ressignificar o papel e o lugar do trabalhador rural, mesmo porque grande parte da população brasileira não vivia no mundo urbano. No discurso nacionalista, o trabalhador emergiria nas figuras do caboclo, sertanejo, jeca-tatu, caiçara, caipira, variantes do elemento rural, passando a ser vistos como cerne e vigor da raça.

Considerando as particularidades e especificidades, este aspecto também foi considerado no caso argentino. Como demonstrou Capelato (2009), no peronismo, o campo também foi exaltado como a expressão do "bom e do belo”, mas não mais como símbolo da pureza original. O campo seria apresentado como lugar de produção, trabalho, prosperidade e desenvolvimento econômico, propiciado pelo Estado. É neste contexto que também se vê a valorização do gaucho argentino, que inclusive emergiu nos discursos

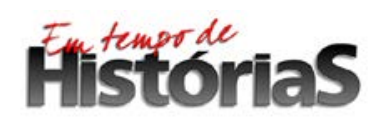


de Perón e em outros meios de comunicação, enquanto "guardiões das tradições”, simbolizando a "argentinidade”.

O segundo aspecto assinalado pelo historiador abarca a preocupação do contexto da década de 1930, marcado por expansionismos territoriais de potências industriais. Segundo Dezemone (2012), a ocupação do território nacional, com amplas parcelas desabitadas e sem integração, denominadas "espaços vazios”, tornou-se uma das preocupações principais do governo de Vargas. Diferentemente, na Argentina, a preocupação advinha dos conflitos rurais, que tomavam notoriedade sobretudo na região pampeana, amplamente ocupada.

Em ambos os países, boa parte da população vivia no mundo rural ${ }^{3}$ então também havia a preocupação em transformar seus habitantes em consumidores diretos e mantêlos em seus territórios. Assim, estamos de acordo com Ribeiro (2008) ao afirmar que, no Brasil e na Argentina, o êxodo rural era visto como um perigo a ser combatido e corrigido com a atuação estatal, pela manutenção da ordem. Conter o superpovoamento das grandes cidades era também controlar o desemprego nestas áreas, já sentido em Buenos Aires que, segundo o censo nacional, em 1947, contava com $45 \%$ da população proveniente do interior, sobretudo mulheres.

Com relação às políticas, em ambos os governos, houve tentativas de incluir estes trabalhadores na legislação. Os anos iniciais do Estado Novo marcaram um declínio nas discussões a respeito da extensão dos direitos trabalhistas no meio rural, sendo retomadas somente nos anos finais do governo, especialmente por uma preocupação política e eleitoral. Na Consolidação das Leis do Trabalho figuravam a carteira profissional, o salário mínimo, o aviso prévio e as férias pagas para os trabalhadores rurais ${ }^{4}$.

Com relação à sindicalização rural, Dezemone (2012) considera que o monopólio da representação presente na legislação, voltada aos trabalhadores urbanos, teria sido estendido para os trabalhadores rurais, conforme podemos observar pelas leis de 1939, que previa a unicidade sindical, o sindicato oficial e a estrutura sindical verticalizada.

\footnotetext{
${ }^{3}$ Os índices estatísticos consideram somente área urbana e rural, sendo que a segunda corresponde à locais com menos de 2 mil habitantes. De acordo com o IBGE, na década de 1940, no Brasil, 68,8\% da população era rural enquanto, na Argentina, segundo o censo nacional do INDEC, de 1947, 37,5\% da população era rural.

${ }^{4}$ Com exceção do Estatuto da Lavoura Canavieira de 1941, todos os decretos específicos ao meio rural foram criados no fim do governo, como: o de $\mathrm{n}^{0}$ 7.038, de 10 de novembro de 1944, de extensão de sindicalização ao campo; o de ${ }^{\circ} 18.809$ de 5 de junho de 1945, tratando da cobertura de acidentes de trabalho na agricultura e na pecuária; e o de $n^{\circ} 7.916$ de 30 de agosto de 1945, proposta de distribuição de terras.
} 
Com relação à questão das terras, Ribeiro (2008) afirma que, nos anos 1940, o governo intensificou a ação da Comissão Especial da Faixa de Fronteiras, no sentido de exigir títulos de propriedade de terras, além de fazer-se mais forte a propaganda da Fundação Brasil-Central, para incentivar a colonização do Centro-Oeste. No caso da Argentina, a questão seria tratada mesmo antes de 1946 e seguiria recebendo atenção nos primeiros dias de atuação no governo. Ainda segundo o historiador, em 1943, Perón iniciou uma política favorável aos arrendatários rurais, através da redução de 20\% e congelamento dos preços dos arrendamentos. Tal política continuaria por todo o governo peronista, facilitando a aquisição de terras a médio prazo pelos arrendatários.

Também merece destaque o Estatuto Del Peón de 1944, em que procurou-se garantir os direitos trabalhistas para os trabalhadores rurais, como salário mínimo, férias de oito dias pagas pelo patrão, assistência médica, bem como um pequeno pedaço de terra para que o agricultor pudesse cultivar. Posteriormente, o Décimo Terceiro Salário e a aposentadoria para os trabalhadores rurais (1954) foram instituídos, assim como o Consejo Agrario Nacional, cujo objetivo era promover a reforma agrária no país.

No tocante à sindicalização rural, diferentemente do Brasil, na Argentina, os trabalhadores dos sindicatos tinham como função fiscalizar a mão-de-obra quanto à efetiva realização do trabalho. Ainda de acordo com o historiador, o movimento sindical era mais atuante na região pampeana e estava construído em moldes similares ao urbano. Sobretudo após 1948, quando o regime precisava aumentar a produção, os sindicatos nas regiões tinham o poder e a obrigação de excluir os bêbados e todos os considerados indesejáveis para o trabalho no campo.

Estamos de acordo com Ribeiro (2008) ao ponderar que, na Argentina, os direitos eram mais assegurados na província de Buenos Aires do que nas províncias dominadas pelos açucareiros, como Salta e Jujuy. Consideramos que o mesmo ocorria no Brasil sendo que, no Rio de Janeiro, a legislação seria mais respeitada do que em outros estados mais afastados da antiga capital, como o caso do Norte e do Nordeste brasileiro.

No que concerne à propaganda política para estas áreas, estudos clássicos como os de Capelato (2009) e de Mariano Plotkin (2013) mostraram que as mesmas ultrapassaram os limites das capitais federais, sobretudo a partir do rádio, dos manuais escolares e das festas cívicas, atingindo as áreas mais distantes do Brasil e da Argentina. Marcela Gené (2008), a partir da propaganda política, e nós mesmos, Lago (2015), a partir

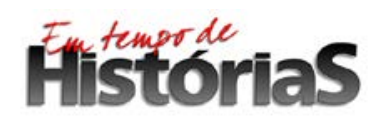


dos discursos políticos dos governantes, também analisamos as mensagens específicas para os trabalhadores urbanos e rurais nestes países.

Do ponto de vista teórico-metodológico, dialogamos com estudos gerais e específicos sobre cartas porque contribuem na nossa reflexão sobre as possibilidades de trabalho e interpretação das cartas. Dos gerais, destacamos o livro organizado por Angela de Castro Gomes (2004) e o capítulo de Teresa Malatian (2015) por partirem de abordagens amplas sobre cartas, que envolvem os questionamentos, como: a autoria e a leitura da carta, as condições e locais em que foram escritas, os códigos sociais utilizados, onde foram encontradas e guardadas e quais temas foram tratados.

Além destes trabalhos, os estudos sobre as cartas aos governantes, no Brasil e na Argentina, contribuíram significativamente para o desenvolvimento deste estudo, inclusive nos motivando nesta empreitada. No caso brasileiro, destacamos os dos historiadores José Rogerio da Silva (1992), Jorge Ferreira (1997), José Rogério Franco Reis (2002) e Vanderlei Vazelesk Ribeiro (2008). No caso argentino, o capítulo do livro do historiador e ensaísta argentino Omar Acha (2013) e o livro recém-lançado da historiadora norte-americana Donna Guy (2017) também são fundamentais.

No tocante à escolha do método comparativo, Maria Ligia Prado (2005), inspirando-se em Marc Bloch, considera que, para comparar, é preciso escolher dois ou mais fenômenos, que pareçam apresentar certas analogias, em um ou vários meios sociais diferentes. Em seguida, descrever as curvas de sua evolução, constatar as semelhanças e as diferenças e, na medida do possível, explicá-las à luz da aproximação entre uns e outros. De preferência, deve-se estudar, paralelamente, sociedades vizinhas e contemporâneas, submetidas, em virtude de sua proximidade, à ação das mesmas grandes causas, remontando a uma origem comum. A leitura criteriosa das fontes deve induzir a formulação de novas questões ou problemas, que permitam o surgimento de novos enfoques e novas interpretações.

No nosso caso, para refletirmos sobre os aspectos comuns e as particularidades dos conflitos e pedidos de terra durante ambos os regimes, assinalando as semelhanças e as particularidades dos casos. Finalmente, este artigo tem duas partes principais, além desta introdução e das considerações finais: na primeira trataremos das estruturas governamentais, que cuidaram das cartas, e na segunda analisaremos os conflitos e os pedidos de terra presentes nas missivas.

\section{Filistororias}




\section{Chamamentos políticos e burocracias estatais}

Em ambos os países, a escrita e o recebimento de cartas ocorreu ao longo dos dois governos. Contudo, no caso argentino identificamos um chamamento político direto e pessoal o que, no caso brasileiro, foi feito de forma indireta e impessoal, isto é, realizado por intermediários como Marcondes Filho, enquanto Ministro do Trabalho, Indústria e Comércio a partir de 1942. A especificidade argentina fez com que demarcássemos dois marcos temporais para este país: 1946, após a apresentação do Primeiro Plano Quinquenal no Parlamento pelo presidente, no dia 21 de outubro; 1951, após o discurso político de Perón promulgado no dia 3 de dezembro. Esse discurso foi irradiado em cadeia nacional de rádio e teve como lema Perón quiere saber lo que su pueblo necessita. No primeiro, Perón solicitava comentários dos argentinos e, em especial, dos trabalhadores sobre um plano que já tinha sido divulgado; já no segundo, como o próprio título do discurso revela, Perón convidava o povo argentino, principalmente os que moravam nas regiões mais distantes, para que enviassem suas “inquietudes” para a elaboração do Segundo Plano Quinquenal ${ }^{5}$.

Com relação ao recebimento da correspondência, no caso brasileiro, elas ficaram sob os cuidados da Secretaria da Presidência da República ${ }^{6}$, regulamentada em 1930, responsável pelo Gabinete Civil e serviços anexos. Apesar das modificações ao longo da Era $\operatorname{Vargas}^{7}$, desde o início o órgão foi pensado de maneira ampla e com diversas subdivisões que serviriam para organizar o Estado, coordenar as atividades com os demais organismos do governo e mediar as relações entre os distintos setores da sociedade, sobretudo a partir da comunicação política do governo.

No caso argentino, as cartas foram recebidas pela Secretaria de Assuntos Técnicos, criada em 1946 e dirigida pelo espanhol Francisco Figueroa. A ST sucedeu o

\footnotetext{
${ }^{5}$ Segue o trecho final do discurso, com a convocação: "No obstante ello, deseo hacer un llamado final a las personas e instituciones, y de manera muy especial a los sindicatos de trabajadores, para que antes de 31 de diciembre remitan a la Presidencia de la República sus petitorios e inquietudes, a fin de ser debidamente estudiados. Toda correspondencia debe ser enviada a la calle 25 de Mayo 11- Capital Federal. (....) Hago, por fin, un llamado a todos los argentinos de bien a fin de que pongan el apoyo de su idea y de su esfuerzo a nuestros trabajos actuales de planeamiento, a fin de que el Segundo Plan Quinquenal sea de todos y para todos” (PERÓN, 1988, p.610).

${ }^{6} \mathrm{O}$ secretário teria prerrogativas de ministro de Estado. Durante os quinze anos de governo Vargas, três tiveram destaque no organismo: Gregório da Fonseca durante o governo provisório, Ronald de Carvalho em 1934, Artur Guimarães de Araújo Jorge, entre 1935 e 1936, e Luiz Vergara, de 1936 até o fim do Estado Novo.

${ }^{7}$ Os serviços da Secretaria seriam reorganizados novamente em 1934 e em 1937.
} 
Conselho Nacional do Pós-Guerra (CNP) ${ }^{8}$ então continuou com amplas competências como planificação, coordenação sistemática e execução de todas as questões vinculadas às esferas financeira, econômica e social. De acordo com Patrícia Berrotarán (2013), a ST tinha um caráter de Ministério, com certa autonomia para lidar com as oposições internas e políticas. Ainda de acordo com a autora, apesar da ideia de planificação de Figuerola ser idealizada como um processo coletivo, construído pelo consenso da maioria, desde o início o secretário detectou fortes obstáculos como a ausência de um núcleo burocrático e técnico competente para implementar ações e realizar o plano de governo. Para lidar com a questão, a Secretaria implementou um programa global e sistemático, voltado para a formação de funcionários. O programa permitia não apenas a formação de um corpo técnico competente, como também procurava doutrinar e controlar político e ideologicamente os funcionários, em especial os que eram identificados como opositores ou inimigos do governo.

Com a nova Constituição de 1949 e a reforma ministerial, a antiga Secretaria foi transformada em Ministério de Assuntos Técnicos da Presidência (MT), sendo o médico Raul Antonio Mende o seu responsável. A partir das atribuições, podemos notar que o órgão era um aperfeiçoamento da antiga secretaria, mantendo ou ampliando algumas das funções anteriores e tendo novas, como a execução do Primeiro Plano Quinquenal e organização do Segundo Plano. A estrutura do MT era muito maior do que a Secretaria brasileira e a anterior argentina, inclusive com mais verba e funcionários. Além deste aspecto, outro diferencial encontrado na documentação é o aprofundamento da “profissionalização" e do “doutrinamento” dos funcionários públicos, além da preocupação com a segurança do organismo. O argumento mais utilizado para a doutrinação, controle e segurança era a elaboração e execução do Segundo Plano Quinquenal, que deveria contar com a contribuição de todos os argentinos e, em especial, dos funcionários deste Ministério, que coordenava a ação dos outros Ministérios e informava, periodicamente, ao executivo o andamento do plano.

Uma das razões possíveis da preocupação com a doutrinação no caso argentino pode ser identificada nos diferentes tipos de regimes no Brasil e na Argentina. Conforme

\footnotetext{
${ }^{8}$ O CNP era uma instância técnico-burocrática, que objetivava realizar estudos sobre a Argentina do período da Segunda Guerra Mundial e as possíveis consequências do final do conflito, estabelecendo estratégias e estudos que foram utilizados como base para o Plano de Realizações e Inversões para o Quinquênio 1947-1951, também conhecido como Plano Perón ou Primeiro Plano Quinquenal argentino.
} 
assinalou Capelato (2009), Vargas não tinha necessidade premente do apoio popular pois negociava com vários grupos da sociedade, além de contar com o apoio das Forças Armadas, que asseguraram a vitória do golpe de 1937. Na Argentina, ao contrário, Perón, após o 17 de outubro de 1945, despontou como o candidato natural das classes trabalhadoras e dos setores médios de baixa renda. Além disto, venceu duas eleições, de 1946 e 1951, com o voto popular. Nestas circunstâncias, o peronismo necessitava do apoio das massas para a sua manutenção no poder, o que acabou por transformar a classe trabalhadora na sua base e força política.

Alguns aspectos da profissionalização dos órgãos e dos funcionários se assemelhavam com às do caso brasileiro, como a opção do ingresso por concurso público, o controle ideológico e a censura aos funcionários que não seguiam ou concordavam com as ideias do regime peronista. Os funcionários dos dois países deveriam seguir diretrizes para trabalhar com os documentos recebidos, também revelando uma preocupação com a padronização e profissionalização dos funcionários públicos. Apesar das particularidades, nos dois países, a preocupação estava inserida em uma conjuntura de extremo controle político e social, decorrente também da crescente oposição aos governantes e de repressão aos opositores. Tal cenário contribuiria para a conformação de um modelo ideal autoritário de funcionário público, que estivesse desconectado da vida política do país.

No que se refere aos trabalhos dos organismos com as cartas, identificamos semelhanças nas diretrizes de como trabalhar com os documentos recebidos. As missivas deveriam ser lidas, sendo que algumas partes, como os objetivos ou os efeitos dos pedidos, eram grifadas de outra cor. Posteriormente, os funcionários faziam um breve relatório sobre as mesmas, classificando-as por temas e assuntos, para então serem enviadas aos demais Ministérios. Os responsáveis pelas cartas nos Ministérios deveriam fazer um novo relatório, constando de uma síntese, considerações e conclusões.

Em ambos os casos encontramos respostas genéricas, e em alguns casos específicas, para os remetentes, o que não significa que todas as solicitações foram atendidas. Em ambos os países, na maioria dos casos, percebemos que era aberto um processo por carta. No caso argentino, isso se evidencia mais, sobretudo quando a sugestão ou o projeto interessava ao Ministério. Nestes casos uma nova carta era enviada ao remetente, solicitando audiência, e, posteriormente, um parecer sobre a mesma. No caso das cartas referentes ao Segundo Plano Quinquenal, em teoria, as melhores propostas seriam incorporadas ao mesmo.

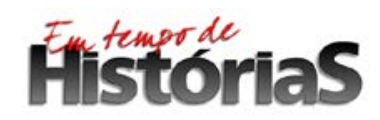

(PPGHIS/UnB) No. 33, Brasília, Ago - Dez 2018 ISSN 2316-1191 
As estruturas mencionadas revelam que, por trás da noção de "diálogo direto” entre o governante e os governados, existiram elaborados aparatos governamentais, com diversos mediadores especializados, que tornaram a sustentação do “diálogo direto” possível. As estruturas também tiveram um papel político importante, pois deveriam refletir a imagem e ideologia oficiais dos regimes, prezando pela eficiência e profissionalização, como um eficiente e amplo canal de comunicação entre o governo central e a sociedade, que ultrapassou sua função meramente administrativa-científica. Assim, as Secretarias e o Ministério também contribuíram para a construção e a sustentação das imagens dos "novos" momentos, tal como de governos eficientes e à serviço de todos os seus cidadãos.

\section{Aflitos Rogamos, imploramos tal caridad: conflitos e pedidos de terra}

Os conflitos e pedidos de terra estão presentes, de forma direta ou indireta, em diversas cartas. Em muitas, os conflitos e pedidos aparecem de forma isolada, mas nós daremos preferência aos que aparecem de forma combinada, isto é, uma expropriação de terra que leva ao pedido de terra ou a ajuda do governo.

Segundo Ribeiro (2008), o decreto 19.482, de 1930, continha dispositivos que tratavam do estímulo à colonização. Ainda de acordo com o historiador, o primeiro tratava dos auxílios para os colonos desempregados das cidades, a serem instalados no campo. O segundo estabelecia a criação de uma contribuição sobre os salários dos servidores públicos, para atender as despesas previstas no artigo anterior.

O propósito de colonizar ganharia mais impulso no Estado Novo. Em agosto de 1938, o decreto 3.010, que regulava a entrada de estrangeiros no país, buscava facilitar a instalação dos mesmos nas zonas rurais. O decreto previa uma cota de $80 \%$ de trabalhadores agrícolas para cada nação imigrantista, além de concessão de créditos para os trabalhadores mais capacitados. Em 1940, o decreto 2.099 estabelecia as condições de núcleos coloniais e, no ano seguinte, o decreto 3.059, organizava as colônias agrícolas nacionais destinadas a receber brasileiros “reconhecidamente pobres”, que deveriam ser localizados no interior do país. Assim, colonizar significava deslocar o excesso populacional das regiões urbanas, que deveriam ser fixados nas zonas rurais, preferentemente próximas aos mercados consumidores, como pequenos proprietários (RIBEIRO, 2008, p. 67).

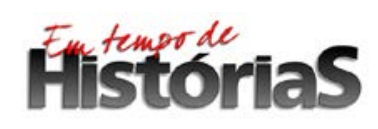


Enquanto no Brasil o Estado Novo tentava atuar em regiões onde antes não chegava a burocracia estatal, na Argentina, a atuação burocrática no meio agrário estava mais voltada para a regulação dos contratos de arrendamentos rurais nas zonas pampeanas. No primeiro caso, era possível vislumbrar a ocupação de uma fronteira a Oeste e uma Amazônia, que se apresentavam como possibilidade de expansão, diferentemente do segundo caso, no qual já havia um latifúndio estruturado.

Em setembro de 1940, Manoel Alexandre da Silva, escreve do interior de São Paulo, solicitando a ajuda do presidente:

Peço em nome de todas as famílias nossas sendo despejadas situadas na fazenda do Estado Pirapo Santo Anastacio município de Presidente Prudente Estado de São Paulo Corrego da Catanduva. Estamos sendo despejados por um (grileiro) calabrez de nome José Milano acompanhado por jagunços armados a carabinas e aqui não tivemos providências. Somos noventa famílias nesta gleba proibidas de trabalhar por jagunços. Esperamos pelo auxílio do nosso nobre chefe ${ }^{9}$.

O missivista utilizou a família e o trabalho para denunciar a injustiça que sofreu. Vale destacarmos que esta não ocorria “somente” com uma família brasileira, mas com noventa, ou seja, era um pedido de amparo individual que representava o coletivo. A injustiça também os impedia de cumprir uma de suas funções no "Brasil novo": trabalhar. A concepção, um dos pilares do discurso oficial, foi apropriada e contribuiu no fortalecimento do argumento e na legitimação da solicitação. Em outras palavras, o pedido era legitimado duas vezes, isto é, porque era justo e pelas pessoas cumprirem os seus papéis para a aplicação do projeto político varguista e a construção do "novo país”. Finalmente, o apelo ao presidente, enquanto “chefe”, representante da casa/do país, que deveria mediar e solucionar os problemas dos seus milhares de filhos/nacionais.

Como se observa, a concepção de injustiça estava relacionada diretamente à desordem local e não nacional. Os remetentes, em muitos casos, identificaram que, o poder central, federal, era mais eficiente do que o local. Deste modo, concordamos com Ribeiro (2008) ao afirmar que, enquanto o primeiro poder representava a justiça e os “novos países”, o segundo poder, em muitos locais, ainda representava os “velhos países”, marcados pelas injustiças e arbitrariedades.

\footnotetext{
${ }^{9}$ AN-SP, lata 320.
} 
Dois meses depois, em novembro do mesmo ano, do interior de São Paulo, Francisco Gomes Neto solicitava a ajuda do presidente diante de uma injustiça: a destruição das suas plantações pela fazenda Brasil Land e a ameaça da polícia aos seus familiares. Ainda que a carta também contenha os aspectos mencionados, diferentemente do caso anterior, o conflito se estabeleceu entre um indivíduo e uma “empresa”. Novamente, a imagem da família e do trabalho são evocados para conformar o argumento e legitimar o pedido de ajuda.

As terras destruídas do missivista podem ser entendidas como uma dupla afronta ao projeto político varguista: primeiro porque a terra, em teoria, deveria ser disponibilizada para os que trabalham nela; e segundo porque a plantação também poderia servir para alimentar a família, que acabou ficando sem sustento pelo o que ocorreu. Finalmente, vale destacarmos a denúncia às autoridades policiais locais, não apenas confirmando o que havíamos comentado sobre as distinções entre o poder "local” e “federal”, mas sobretudo evidenciando as distintas realidades sociais do “novo Brasil”, que ainda não tinham chegado em todos os lugares.

A maioria dos telegramas encontrados até o momento tratavam de conflitos que envolviam problemas com grileiros e denúncias de vizinhos. No que se refere aos vizinhos, Kalil Mutran, escreve do Pará, em maio de 1941:

Deste pedaço longicuo terra brasileira, desta terra boa, dadivosa, qual elegi Patria meu coração por que é patria minha numerosa família, apelo vossencia sentido evitar seja minha família prejudicada pretensão absurda de uma visinha de nome Perina Gomes que requereu Vossencia mais terras do que ocupava este município, com grave prejuízo suplicante ocupante.

Pretende Perina possuir mais 20 annos, onde possue bemfeitorias de vulto. Tambem tem serviço cultura grande número de trabalhadores brasileiros pois Perina Gomes apenas sempre ocupou 4030 metros frente.

Quando requereu uma légua sabendo ia prejudicar suplicante, entrando sua demarcação casa moradia, capinzaes, roças, demais benfeitorias minha propriedade modo tenho deixar tudo mãos mesma retirar-me com meu prejuízo toda minha família composta dez brasileiros ${ }^{10}$.

${ }^{10}$ AN-SP, lata 13. 
A súplica e a denúncia do imigrante são forjadas com base na exaltação do Brasil, das concepções de família e de trabalho. Kalil inicia sua carta elogiando o Brasil e mostrando que, dentre as opções, escolheu viver no país. Em seguida, diz ser brasileiro pelo coração e por ter uma família numerosa de brasileiros. Segundo o missivista, a injustiça é pautada na desigualdade social, cultural e econômica entre a vizinha e ele. No caso da vizinha, ele menciona não apenas as posses materiais, como também as imateriais, relacionadas à cultura e instrução. Kalil estrutura seus argumentos de forma a assinalar a vaidade e o egoísmo da vizinha que, mesmo com todos os bens mencionados, ainda quer se apropriar de uma terra que está ocupada por uma família grande.

No que se refere à desocupação, o argumento também é sustentado pelo destrato ou a falta de consideração aos preceitos do projeto político varguista, como a questão da terra/produção, do trabalho para o progresso do Brasil e da importância das famílias. Kalil encerra sua carta apelando para o discurso oficial e evocando as imagens de clarividência, justiça e bondade do presidente, que possibilitariam a resolução do caso.

A partir dos anos 1940, encontramos um número maior de cartas em que os missivistas denunciavam os casos de injustiça e exigiam uma ação do governante, como Manoel Cezario, que escreveu ao presidente em 1941, da Bahia, para tratar da expulsão dos trabalhadores agrícolas do terreno que cultivavam:

Rogo vossencia interceder urgente junto a Justiça Trabalho aqui afim ser resolvida questões trabalhadores agrícolas pobres expulsos proprietários terrenos, indenização suas lavouras. Pobres carregados filhinhos estão esmolando. Uso proprietários meterem animais roças trabalhadores reconhecendo pobreza justiça civil, qual acontece Rufino Ferreira filiado Sindicato Rurais Trabalhadores fazenda Freguesia Matuim, propriedade Raimundo Nonato Santos Cia, despedido caprichos. Dada queixa Delegacia Ministerio Trabalho resolver. Pedimos leis, terrenos, evitar questões proprietários e pedimos fineza responder $^{11}$.

Manoel inicia sua carta sem fazer saudação ao presidente e mostrando que conhecia as instâncias governamentais, que inclusive já havia acionado. Contudo, seja pelo grau da instância ou pela ineficiência, ele também opta por escrever ao presidente, para não apenas solicitar como reivindicar os direitos dele e dos demais trabalhadores

${ }^{11}$ AGN-MT, caixa 456.

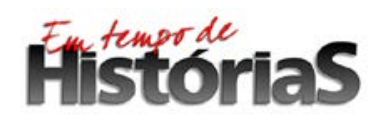

(PPGHIS/UnB) No. 33, Brasília, Ago - Dez 2018 ISSN 2316-1191 
pelas terras que trabalhavam. As noções sobre a família desamparada e o trabalho continuam perpassando a argumentação, a fim de legitimar e alcançar o pedido.

O diferencial desta carta também está na lista dos pedidos finais, especialmente na solicitação da "fineza” da resposta do presidente. Esta parte final da carta revela que, apesar da estrutura mencionada no primeiro tópico, a resposta da carta não chegou. A insistência de parte dos trabalhadores em ser escutado é um aspecto que merece ser assinalado, tal como a noção de que, se não tiveram resposta, o responsável não era Vargas, mas sim algum funcionário ou algum entrave nos correios, o que também pode ser observado no caso argentino.

Além dos conflitos com vizinhos e empresas, também figuram os com autoridades policiais e o próprio Estado, como o caso de João José de Oliveira, que escreve de Minas Gerais, rogando ao presidente:

Conhecendo coração humano V.Excia, peço socorrer afim não sermos judiados pela polícia espirituosamente . Sou pai família estou fora de casa porque polícia intimou largar minha casa entregar outro, dizendo se voltar apanharei. Com centenas de pais assim tem sucedido, pedindo providencias sem resultado. Estamos sem garantia por sermos moradores norte Rio Doce município Conselheiro Pena, Estado Minas Gerais ${ }^{12}$.

O missivista denuncia o abuso policial que, embora pareça um caso isolado, constitui parte da realidade dos pais de família que ali viviam. Esta também revela a falta de alternativa na cidade e a ausência de uma autoridade a quem o missivista e os demais poderiam recorrer. Nesta situação e "conhecendo o coração humano" de Vargas que o trabalhador pede a ajuda do governante.

Caso similar, mas com o interventor federal do Piauí, foi mencionado por José Conrado de Andrade Sobrinho, que teve suas terras retiradas e entregues ao interventor. De acordo com o missivista, ele tinha a escritura e estava em dia com os impostos, mas estes aspectos não foram suficientes para que a terra lhe fosse arrancada. Ademais, José havia entrado na justiça, no entanto, segundo ele, a mesma privilegiou o Estado, negando não apenas seu pedido, mas principalmente desrespeitando as leis brasileiras. Ante as injustiças mencionadas que ele recorre ao presidente que, aparentemente, também não respondeu.

${ }^{12}$ AGN-MT, caixa 
Sobre os usos de determinados imaginários políticos do discurso oficial, estamos de acordo com Ferreira (1997) ao afirmar que os trabalhadores, quando manipulavam o arcabouço doutrinário varguista, selecionavam aquilo que poderia beneficiá-los, deixando de lado todo o aparato autoritário, repressivo e excludente. Por essa razão, para o historiador, não é casual que nos escritos da época, os trabalhadores fizessem referência ao “coração humano” de Vargas e não à repressão política, às prisões arbitrárias, à tortura policial ou às perseguições aos comunistas. No entanto, também é preciso considerar as subjetividades dos que escrevem, que revelam identificações de alguns com o projeto político e da capacidade de controle limitada sobre o que se diz, isto é, na escrita está presente o que quer dizer e, efetivamente, diz, mas também expressa o que não quer dizer. Em outras palavras, também estamos de acordo com Gomes (2000) ao dizer que a escrita, enquanto construção, pode conviver com falhas e enganos, fraudes e ilusões, erros e mentiras.

As denúncias dos abusos das autoridades locais e da ineficiência de algumas instâncias burocráticas também apareceram nas cartas da Argentina peronista. Andrés escreve sobre um caso individual, mas que representava uma situação de diversas famílias de uma ilha que a província de Entre Rios estava interessada e, por isso, desapropriou os seus moradores. De acordo com o missivista, a terra era ocupada há mais de noventa anos, desde os tempos dos seus avós, sendo que a concessão do terreno e a escritura foram fornecidas pelo Estado, via instâncias de Buenos Aires. Contudo, Andrés conta que seu pai foi chamado em um dos órgãos públicos da ilha a fim de comprovar que era realmente o dono da terra. Ao comprovar, as autoridades apreenderam os documentos e entraram com um processo contra o pai de Andrés, exigindo as terras.

Andrés e o pai tentaram resolver a questão em várias instâncias federais e locais, mas não obtiveram sucesso, até que o pai dele “faleceu de desgosto”. Ante a não solução do caso, ele resolve escrever ao presidente, em 1946, de Buenos Aires, para denunciar o caso da ilha em San Nicolás, pedindo justiça pelo pai e pela terra desapropriada:

Nos vamos a permitir contra toda nuestra manera de ser molestar su atención que nos suponemos que en estos momentos, son muy numerosas, para organizar la Republica, por esta causa le pedimos toda clase de disculpa, y deseamos que este asunto que le vamos a plantear, lo delegue, por donde corresponda, con el encargo, de que se nos haga justicia, 
que lo único que le pedimos encarecidamente (...) Somos verdaderos criollos de pura sepa, muy pobres, pero honrados $(\ldots)^{13}$.

Assim como no caso brasileiro, a escrita ao presidente foi propiciada por uma situação de extrema aflição e injustiça. O argumento também é marcado pela questão da falta de justiça, encabeçada pelos órgãos responsáveis. O diferencial desta carta é que Andrés se utiliza do passado, antes mesmo de Perón ser eleito, para argumentar que já havia ajudado o então presidente, quando o mesmo precisava de apoio, afirmando que, neste momento, era Andrés que precisava, como "peronista das antigas".

Andrés não se utiliza apenas da identidade política, mas também da identidade nacional e social, tão evocadas pelo discurso oficial, em que os crioulos e os humildes deveriam ser escutados. Apesar das condições desfavoráveis, Andrés mostra que tem conhecimento das burocracias da Argentina peronista e garante que esgotou todos os recursos antes de "molestar o presidente".

O encaminhamento do caso, datado de julho do mesmo ano, revela que o órgão federal tentou tomar alguma atitude sobre o assunto, solicitando explicações dos órgãos envolvidos e o envio do comprovante de recebimento da carta. Apesar de não termos encontrado a resposta oficial do governo, observamos a tentativa do trato do caso, tal como a importância da resposta ao remetente, ainda que deixando a cargo da província de Entre Rios.

Sobre o envio das cartas, Girbal-Blacha (2011), ao analisar as cartas dos habitantes da província do Chaco, pondera que muitas não chegaram para os governantes, ficando arquivadas nas secretarias de governo e nas Comissões de Fomento. De acordo com a historiadora, o arquivamento das cartas revela os filtros exercidos pelas autoridades locais para determinados tipos de ação e solicitação popular. As autoridades evitam assim expor a tensão de suas próprias posições políticas ante o governo central. Consideramos que este tipo de ação também pode ter ocorrido em outras províncias argentinas, sendo mesclada com as grandes distâncias e a perda das cartas no meio do caminho.

Em dezembro, do mesmo ano, Teófila Garay, de Missiones, também solicita ajuda no seu caso:

${ }^{13}$ AGN-MT, caixa 468.

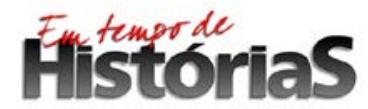


Teofila Domingues Garay, de 77 años de edad, oficio lavandera, domiciliada en Chacra $\mathrm{n}^{0} 1$, calle Morioni $1 / \mathrm{n}$ de esta ciudad se dirige respetuosamente al Exmo $\mathrm{Sr}$ evaluando la siguiente consulta; hace 17 años que vivo con el permiso del dueño quien ya a muerto hará 7 o 8 años clave mi ranchito, sin cobrarme ningún alquiler, ahora se me presenta un señor, pidiéndome el desalojo, evocando su derecho de haber adquirido en compra el citado lote. ¿'Tendrá derecho para tal procedimiento dejandome en la calle? porqué me recuso no me dan ni siquiera para mandar demolir mi vivienda y mucho menos para hacer conducir en otro lugar y clavarme de nuevo ${ }^{14}$.

Teófila apela ao presidente argentino ante uma injustiça: a desapropriação da terra que sempre trabalhou. Evocando dois dos pilares chave da Argentina peronista- o trabalho e a moradia-, a missivista pergunta ao presidente se a pessoa teria o direito de lhe expulsar, tirando seus bens mais preciosos, sem lhe dar alguma contribuição financeira em troca, deixando-a na rua.

As duas cartas revelam os aspectos comuns com o caso brasileiro, sobretudo no que se refere à concepção de justiça e a distinção entre o poder local e o federal. Sobre a concepção, tanto Andrés quanto Teófila consideram que seus pedidos, por estarem amparados e em consonância com determinados aspectos do discurso oficial, por si só, já deveriam ser atendidos uma vez que ambos estão amparados na noção de justiça social tão evocada pela propaganda peronista.

Em tom diferente de Teófila, o povo vizinho de Quili Malal, do extremo Oeste de Neuquén também escreve para Perón, em 1946, reivindicando o documento em que conste a aprovação da posse de terra e outros pedidos relacionados ao território, como o apoio financeiro governamental para algumas obras públicas:

Por decreto del Ministerio de Agricultura de la Nación del 2 de diciembre de 1938 se dispuso tratar en el lugar que habitan los peticinantes, un pueblo, cuya denominación se oficializó por decreto del Poder Ejecutivo n 44.902, del 26 de octubre de 1939- al tomarse tal resolución se habrá tenido en cuenta que es una población antigua, ubicada en un valle en la margen derecha del rio Agrio, donde la existencia de varios factores favorables aseguran la prosperidad de la zona. Como consecuencia del decreto, a que se hace referencia, en el año 1940, personal de la Dirección de Tierras efectuó el trazado del

${ }^{14}$ AGN-MT, caixa 599.

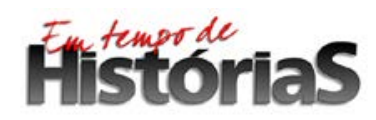

(PPGHIS/UnB) No. 33, Brasília, Ago - Dez 2018 ISSN 2316-1191 
pueblo, pero según todas las informaciones que se han podido obtener, a pesar del tiempo transcurrido no se ha aprobado dicha mensura ${ }^{15}$.

Na carta coletiva, os remetentes explicam a forma particular de atuação e participação política no espaço que ocupam, de maneira específica, e no projeto da "Nova Argentina”, de maneira geral, demarcando o tom reivindicatório da carta, que se contrasta com as analisadas anteriormente. O “povo de Neuquén” se utiliza da história da região, do aparato legal e de aspectos relacionados ao limitado desenvolvimento da área para legitimar a reivindicação da posse da terra pelo seu povo. A ausência dos usos das expressões e dos lemas peronistas para fazer a reivindicação de sua terra e as melhorias necessárias também é emblemático.

A reivindicação é seguida por uma série de comentários a respeito do trato e cuidados da terra e da região, mostrando que estão cuidando, plantando e trabalhando pela terra, ou seja, mostrando que estão "fazendo a parte deles" para a construção da “Nova Argentina”, mas que os governos local e federal não estão "fazendo a sua parte”, que é tão importante no processo quanto a dos habitantes, evidenciando o pacto político acordado por ambas as partes. A partir destes comentários que o “povo de Neuquén” termina a carta sintetizando as suas solicitações ao presidente, como a melhoria da infraestrutura do local.

A Sociedade Cooperativa Agropecuária de Balcarce também escreve para Perón em 1946, solicitando o acesso à terra. O argumento é construído a partir da tríade já mencionada- a terra, o trabalho e a família-, a fim de legitimar a solicitação e serem atendidos. Ademais, o conhecimento e os comentários sobre o Conselho Agrário Nacional local também devem ser destacados, uma vez que revelam como sabiam o que estava acontecendo, de que forma e o não conformismo com a situação. Ao se colocarem como “verdadeiros trabalhadores”, também ressaltavam a preferência que deveria ser dada para aqueles que melhor se encaixavam no projeto peronista. De acordo com a Sociedade, os pedidos dos trabalhadores se apoiavam em dois desejos: um amparado na coletividade e no projeto político peronista, que tinha como lema "hay que producir más", e o outro no âmbito mais pessoal, de sobrevivência.

${ }^{15}$ AGN-MT, caixa 456. 
Além dos aspectos mencionados, os trabalhadores também ressaltavam que tinham o material e as condições para contribuir para a construção da "Nova Argentina”, faltando apenas a terra. Assim, a solicitação da terra vinha acompanhado do pedido de modificação dos planos de parcelamento projetados, para que se tivesse o melhor aproveitamento destas terras, assim como a modificação da cessão por arrendamento vitalício que, para eles, não era favorável para os que mais desejavam trabalhar.

Teófila, de La Rioja escreve em 1951, solicitando a mediação de Perón para a não expropriação da sua terra. A missivista inicia sua argumentação a partir de sua condição de mulher, viúva, mãe e pobre, deixando de lado os lemas peronistas para fazer sua solicitação. Após esta introdução, ela apresenta o seu problema- a possível expropriação de sua terra- e a solução do mesmo- a mediação do Estado, via Perón, enquanto "pai dos pobres”. As imagens do presidente e de seu governo são baseadas em aspectos religiosos e de justiça, encontrando correspondência com o próprio imaginário político produzido pelo discurso oficial.

A concepção da terra- para quem trabalha nela- e de família também estão presentes na carta de Teófila. Assim como nos casos anteriores, o pedido foi amparado tanto nestes pilares de terra, trabalho e família como sustentado pela concepção de justiça. Teófila recebeu uma resposta positiva ao seu pedido em outubro do mesmo ano.

Vale destacarmos que, embora muitas vezes as autoridades locais e federais tenham sido identificadas como injustas e ineficientes, a mesma identificação sobre o governante não ocorria ou pelo menos não aparecia na argumentação dos remetentes. É como se Perón não soubesse e não fizesse parte da ineficiência e das injustiças cometidas pelo seu próprio aparato estatal. Tal como no caso brasileiro, consideramos que a ausência de identificação dos governantes ou mesmo menção da mesma nas cartas, no caso argentino, também pode ser entendida como estratégia argumentativa, uma vez que alguém que está querendo ser atendido tem de seguir certos preceitos, ou pela subjetividade dos remetentes, considerando as possíveis identificações políticas e a ausência de um controle total sobre a escrita.

No que se refere aos pedidos de terra, além dos casos mencionados e de outros que eram para uso pessoal, destacamos pedidos que visavam outros fins, como os projetos para chácaras e para a construção de escolas, algo que ainda não encontramos no caso brasileiro. 
Os representantes do Centro Agrario Yerbatero Argentino (C.A.Y.A), da Federación de Cooperativas Agrícolas de Misiones (A.C.A.M) e da Asociación Rural Yerbatera Argentina (A.R.Y.A), organizações que atuavam em Missiones e no norte de Corrientes, representando mais de oito mil produtores de erva mate, escreveram para Perón em 1946. A proposta era apresentar um plano para a construção de chácaras experimentais, em várias regiões do país, que deveria ser encabeçado pelo Ministério da Agricultura. Além do Ministério, estas organizações também poderiam contribuir no projeto, em determinados territórios da nação.

A proposta de criação das três escolas-granjas em Missiones, para ensinar os filhos dos colonos e orientar os agricultores no processo da produção e cultivo, era baseada em uma argumentação que é composta por um histórico da atuação das organizações na região, da relação das mesmas com o governo, de dados estatísticos e da menção as leis governamentais. Todos estes aspectos contribuem para a legitimação do projeto proposto e da exigência que a lei referente ao cultivo e venda de erva mate não fosse alterada. Tal como a do “povo de Neuquén”, o tom reivindicatório e legitimador não está amparado nos lemas ou consignas peronistas. Em outras palavras, os trabalhadores escrevem legitimados apenas por conhecerem e habitarem a região do cultivo e por saberem como aperfeiçoar os ganhos econômicos para a região, de maneira específica, e para a Argentina, de maneira geral, o que já parecia suficiente para que fossem atendidos.

As noções de participação e atuação mais ativas na construção da "Nova Argentina” ficam mais evidenciadas nas cartas argentinas do que nas brasileiras. Esta diferença pode ser identificada tanto pelas particularidades conjunturais, como os distintos contextos e regimes políticos, como também pelas próprias especificidades dos chamados políticos.

Outra proposta de construção de chácaras foi a de Laurentino Simon Salazar, auxiliar de correios e telecomunicações, mas segundo ele com grande experiência no campo, que escreve de Buenos Aires, em 1951. Na carta, ele sugere o aproveitamento maior das terras improdutivas, a partir de um projeto intitulado "Chácara Justicialista”:

Visto, los deseos de nuestro gran Presidente que quiere que su pueblo diga a su criterio, en el segundo Plan Quinquenal lo que conviene para el engrandecimiento de la patria, en esta Nueva Argentina Peronista, y como todo buen criollo, que desea el engrandecimiento económico del país, debe cooperar con nuestro Presidente para afirmar en cimentos solidos y duraderos la independencia económica, la soberanía política y la 
justicia social, que al decir del General Perón la grandeza de la patria se hará con el trabajo fecundo de sus hijos. En consecuencia presento este proyecto con el título de Chacra Justicialista. El que suscribe Auxiliar de Correos y Telecomunicaciones, con un amplio conocimiento sobre el campo y la avicultura, que a mi criterio traería aparejada una serie de beneficios para la Nación, el refinamiento de la Avicultura etc, etc, etc, y se resolvería las aspiraciones de miles de empleados nacionales, en su carácter de los mismos, nunca pudieron formar un capital para dedicarse en algo productivo y hoy con la Nueva Argentina y la visión de Nuestro Presidente, para el Segundo Plano Quinquenal. Hay un diez por ciento de jubilados y retirados que pueden dedicarse en ese nuevo renglón para el bien de la economía nacional. ${ }^{16}$

Laurentino começa a carta respondendo ao chamado político de Perón. Sua “resposta” é produzida a partir da apropriação das noções de novo país e de outros lemas peronistas para justificar e legitimar seu projeto de lei. Apesar de Laurentino não ser propriamente um trabalhador rural, ele sugere a construção dessas chácaras, que estariam vinculadas ao Ministério da Agricultura e serviriam de escolas agrícolas para todos os que quisessem se dedicar as atividades agropecuárias. Ademais, as chácaras deveriam estar aos cuidados dos aposentados, sendo que o Ministério da Previdência deveria cuidar desta distribuição.

Além da sugestão, é preciso destacar a percepção de Laurentino sobre o campo e os aspectos mais simbólicos que, ao seu ver, contribuiriam de maneira mais profunda para o seu desenvolvimento. De acordo com o missivista, a partir da construção dessas chácaras também seria possível a constituição de uma "corrente de intelectualidade”, transformando o campo em um “ambiente de maior cultura social”, já que, segundo ele, a cidade iria para o campo. Deste modo notamos que, para alguns argentinos, o campo ainda era visto como um lugar de "atraso intelectual e cultural”, que deveria ser educado pelos “homens da cidade”, “civilizados”, que levariam a “cultura” presente na cidade para o campo, auxiliando também no desenvolvimento econômico da região.

Laurentino encerra a carta com o "otimismo" de que sua proposta seja atendida, uma vez que é sustentada por seu “espírito peronista”. Como podemos notar, as noções e os usos da identidade política, do movimento e do "sentimento" peronista variaram em

${ }^{16}$ AGN-MT, caixa 458.

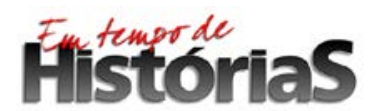


cada caso. No caso de Laurentino, um dos significados que poderiam ser extraídos é que o "espírito de peronista” correspondia ao de quem quer contribuir para o engrandecimento da pátria e para a construção da “Nova Argentina”.

Com relação as apropriações e as ressignificações da identidade e cultura política, consideramos que a noção é construída a partir de uma influência mútua, de governo e trabalhadores, a partir de uma convergência mais ou menos espontânea de ideias, aspirações e demandas próprias, que produzem formas muito específicas dos usos dos termos, expressões e dos imaginários políticos peronistas pelos trabalhadores, coincidindo com a compreensão da cultura política no plural, conforme assinalou Rodrigo Pato Motta (2009). Neste caso, a pluralidade contribui para pensarmos os distintos significados e usos da mesma pelos trabalhadores, especialmente quando nos deparamos com a diversidade das regiões argentinas que os trabalhadores provinham e com as distintas experiências destes trabalhadores, o que interfere e influencia na própria conformação dos peronismos, no plural, que ficariam mais evidentes no segundo governo e, principalmente, após o golpe de 1955.

\section{Considerações Finais}

As estruturas governamentais estavam inseridas nas concepções dos discursos oficiais e em projetos políticos mais amplos, de organização e profissionalização dos funcionários e dos órgãos estatais no Brasil e na Argentina. Apesar das especificidades e particularidades dos casos, em ambos os países tiveram um caráter autoritário, que foi revelado por meio da exigência de um tipo ideal de funcionário público, que deveria ser controlado, censurado e teria uma punição maior se fosse identificado como "inimigo da pátria”.

Estes órgãos também revelam que, por trás da noção de “diálogo direto” entre o governante e os governados, existiram elaborados aparatos governamentais, com diversos mediadores especializados, que tornaram a sustentação do “diálogo direto” possível. As estruturas também contribuíram para as imagens produzidas no momento como de governos eficientes, de trabalhadores e à serviço de todos os seus cidadãos.

Apesar da correspondência entre governante e governados anteceder os governantes brasileiro e argentino, consideramos que o diferencial destes governos pode ser encontrado nos instrumentos (re) criados, na profissionalização do trato das cartas e na valorização e nos usos das mesmas por estes regimes. Os distintos “chamamentos 
políticos” dos governantes também são um aspecto que consideramos relevante e que contribuiu para a intensificação da correspondência enviada.

Consideramos que as missivas devem ser compreendidas à luz das relações específicas e desiguais que compunham os rituais varguista e peronista. A partir da análise observamos que as mensagens dos discursos oficiais não chegaram da mesma maneira e tampouco significaram as mesmas coisas ou foram utilizadas da mesma forma por todos os trabalhadores. Eles se apropriaram, ressignificaram e usaram das mesmas, de acordo com suas experiências e vivências, isto é, a partir das suas práticas e necessidades, atribuindo sentidos muito particulares e variados aos projetos e culturas políticas do momento, variando inclusive de região para região.

Apesar das particularidades destes espaços simbólicos, identificamos aspectos comuns das cartas. Em ambos os casos, a grande maioria dos remetentes argumentou que escrevia baseado em suas experiências, vivências e percepções do que em estudos analíticos. O papel central do Estado- enquanto interventor, mediador ou solucionador da situação-, as noções de construção nos dois países, as ideias de coletivo para atingirem o progresso econômico e os usos dos discursos oficiais também merecem destaque.

Com relação as particularidades, no Brasil, a maioria das cartas estudadas são mais objetivas e, em geral, de sindicatos enquanto, na Argentina, a maioria das cartas é mais longa, detalhada, e, em geral, de pessoas que não se identificaram como representantes de sindicatos ou associados à algum tipo de organização política. Ademais, quando comparamos os tons das cartas brasileiras e argentinas percebemos que os trabalhadores argentinos reivindicaram de forma mais direta e, por vezes, enfática do que os brasileiros, que procuraram reivindicar de outras formas.

Seja por acreditarem ou por usarem estrategicamente, eles procuraram atuar politicamente e reivindicar seus espaços nos projetos políticos de seus países a partir das possiblidades e brechas encontradas. Os trabalhadores escreveram em situação de grande aflição, recorrendo aos presidentes por acreditarem que eles eram a última esperança. A grande maioria também escreveu denunciando situações de injustiça, que estavam em desacordo com os projetos políticos e as “novas” realidades e, portanto, deveriam ser atendidos. Apesar da polissemia das imagens, os governantes eram identificados como os grandes mediadores, solucionadores e justiceiros do Brasil e da Argentina.

Finalmente, as cartas também revelaram as distintas percepções da atuação dos governos locais e federais, sendo os primeiros representantes das “velhas” realidades 
enquanto os federais os representantes das “novas”. Também percebemos as limitações das atuações governamentais nestes rincões, revelando que ainda tinham realidades identificadas como dos “velhos” momentos e países.

\section{Referências bibliográficas}

\section{Fontes}

Cartas Argentinas

Archivo General de la Nación, fundo Secretaria Técnica $1^{\circ}$ y $2^{\circ}$ de la Presidencia del teniente general Juan Domingo Perón, caixas 455-679.

Cartas Brasileiras

Arquivo Nacional, fundo Secretaria da Presidência da República, latas 13, 69, 88, 89, 164, 171, 174, 320 , 456, 457 e 467.

Discursos Políticos

Perón quiere saber lo que su pueblo necesita. Discurso político de Juan Domingo Perón de 3 de dezembro de 1951. In: PERÓN, Juan Domingo. Obras completas del General Juan Domingo. Discursos de Juan D. Perón, 1950-1951. Buenos Aires: Unión del Personal Civil de la Nación, s/d.

\section{Censos}

Censo Nacional de 1940 (Brasil).

Censo Nacional de 1947 (Argentina).

ACHA, Omar. Crónica sentimental de la argentina peronista. Sexo, inconsciente e ideología, 1945-1955. Ciudad Autónoma de Buenos Aires: Prometeo Libros, 2013.

BERROTARÁN, Patricia. “José Figuerola. El estadígrafo de Perón”. In: REIN, Raanan; PANELLA, Claudio. La segunda línea: liderazgo peronista 1945-1955. Ciudad Autónoma de Buenos Aires: Pueblo Heredero; Sáenz Peña: Universidad Tres de Febrero, 2013.

CAPELATO, Maria Helena Rolim. Multidões em cena: propaganda política no varguismo e no peronismo. São Paulo: Editora UNESP, 2009.

DEZEMONE, Marcus. "Mundo rural e Era Vargas: direitos, papel do campo e legislação social na historiografia recente”. Tempos Históricos, vol. 16, pp.219-245, 2012.

FERREIRA, Jorge. Trabalhadores do Brasil: o imaginário popular 1930-1945. Rio de Janeiro: FGV, 1997.

GENÉ, Marcela. Un mundo feliz: imágenes de los trabajadores en el primer peronismo 1946-1955. Buenos Aires: Fondo de Cultura Económica; Universidad de San Andrés, 2008.

GIRBAL-BLACHA, Noemí M. Vivir en los márgenes. Estado, políticas públicas y conflictos sociales. Rosario: Prohistoria Ediciones, 2011.

GOMES, Angela de Castro. "O ministro e sua correspondência: projeto político e sociabilidade intelectual “. In: GOMES, Angela de Castro (org). Capanema: O ministro e seu ministério. Rio de Janeiro: Editora FGV, 2000 ,

A escrita de si, a escrita da história. Rio de Janeiro: Editora FGV, 2004.

GUY, Donna. La construcción del carisma peronista. Cartas a Juan y Eva Perón. Ciudad Autónoma de Buenos Aires: Biblos, 2017.

LAGO, Mayra Coan. Trabalhadores do Brasil, Mis Queridos Descamisados: a (re) invenção dos trabalhadores no varguismo e no peronismo. Dissertação de Mestrado (Mestrado em Integração da América

\section{Filistorias}


Latina)- Programa de Pós-Graduação Interunidades em Integração da América Latina da Universidade de São Paulo-SP. 2015.

MALATIAN, Teresa. “Cartas- Narrador, registro e arquivo”. In: PINSKY, Carla Bassanezi; LUCA, Tania Regina de (org). O historiador e suas fontes. São Paulo: Contexto, 2015.

MOTTA, Rodrigo Patto Sá. "Desafios e possibilidades na apropriação de cultura política pela historiografia”. In: MOTTA, Rodrigo Patto Sá (org). Culturas políticas na História: novos estudos. Editora Fino Traço: Belo Horizonte, 2009.

PLOTKIN, Mariano Ben. Mañana es San Perón: propaganda, rituales políticos y educación en el régimen peronista (1946-1955). Sáenz Peña: Editorial de la Universidad Nacional de Tres de Febrero, 2013.

PRADO, Maria Ligia Coelho. "Repensando a história comparada na América Latina”. Revista de História, n, 153, 2005, pp. 11-33.

REIS, José Rogério Franco. “Não existem mais intermediários entre o governo e o povo”: correspondências a Getúlio Vargas- o mito e a versão (1937-1945)”. Tese de Doutorado. Universidade Estadual de Campinas: Campinas, 2002.

RIBEIRO, Vanderlei Vazelesk. Cuestiones Agrárias en el Varguismo y El Peronismo. Quilmes: Universidad Nacional de Quilmes, 2008.

SILVA, José Rogério da. “Condições de vida da classe trabalhadora na cidade de São Paulo, durante o Estado Novo”. Dissertação de Mestrado. Pontifícia Universidade Católica de São Paulo: São Paulo, 1992.. 